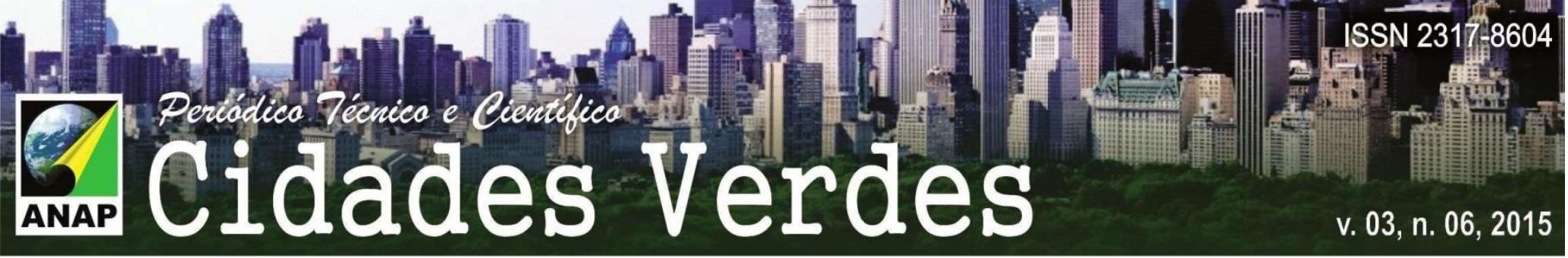

Titulo do Trabalho

\title{
A SUSTENTABILIDADE NO MUNICÍPIO DE RORAINÓPOLIS/RR ATRAVÉS DO CIPÓ TITICA E DA FIBRA DA PALHA DO BURITI.
}

Nome do Autor (a) Principal

Felipe Melo de Souza

Nome (s) do Coautor (a) (s)

Catarina de Fátima Ribeiro

Antonia Flávia Bezerra Marques

Nome (s) do Orientador (a) (s)

Dr. Antônio Tolrino de Rezende Veras

Instituição ou Empresa

Universidade Federal de Roraima

Instituição (s) de Fomento

E-mail de contato

felipe.melo@ufrr.br

Palavras-chave

Sustentabilidade; buriti; cipó titica.

INTRODUÇÃO

Esta pesquisa foi realizada em 2008, no município de Rorainópolis, município do Estado de Roraima criado em 1995, a partir da instalação da vila do Instituto Nacional de Colonização e Reforma - INCRA, onde atraiu na época pessoas de 
diferentes partes do Brasil, com predominância de Maranhenses. O município está localizado a 263,30 km da Cidade de Boa Vista/RR possuindo as vilas: Martins Pereira, Nova Colina, Equador, Jundiá, Santa Maria do Boiaçu.

Esta pesquisa foi realizada na vicinal 30, assentamento Agrário Anauá no município de Rorainópolis, próximo a vila nova colina, vila com cerca de 1510 habitantes, segundo o IBGE, onde o intuito foi de estudar como a comunidade utilizava o cipó titica e a fibra da palha do buriti como fonte de renda, a partir da fabricação de peças de artesanato, que são comercializadas ainda no estado de Roraima e em outros estados do Brasil.

Nessa pesquisa foi acompanhado o trabalho do grupo de mulheres agricultoras, denominada "mulheres toda a fibra", grupo este que é composto de mulheres agricultoras, filhos e filhas pertencentes ao assentamento agrário, sendo que ano de 2009, conquistamos o prêmio do projeto Interações Estéticas e residências artísticas em Pontos de Cultura - Funarte/SCC - região norte, projeto este que consistiu no trabalho de acompanhamento de todo o processo de produção das peças de artesanato, bem como a inserção de alguns elementos naturais as peças, como forma de melhorar e valorizar a sua comercialização.

Nesse processo são utilizados como matéria prima o cipó titica e a fibra da palha do buriti, que são extraídos da própria comunidade da vicinal 30, a partir da coleta das áreas pertencentes as próprias agricultoras que em regime de multirão fazem a coleta da matéria prima.

Durante esse período foram analisados o processo do início até o término final das peças que eram compostas de cestarias, tapetes e vasos artesanais, utilizando produtos naturais e industriais na fabricação das peças.

\section{OBJETIVOS}

O projeto consistiu em analisar o processo de fabricação de peças artesanais com a utilização do cipó titica e fibra da palha do buriti, encontrado na própria área de residência do grupo de mulheres toda a fibra. 
Nessa etapa ainda foi utilizado a adição de urucum para a inserção da cor vermelho rubi, além da folha do crajiru de cor amarelada, esse processo foi utilizado pela primeira vez durante essa pesquisa, sendo de forma geral aceita e executada pelo grupo durante esse processo de tratamento e coloramento da fibra e da palha do buriti.

$\mathrm{Na}$ terceira etapa temos a fabricação dos produtos, que incluem a fabricação das peças como cestarias, vasos e tapetes, sendo os tapetes feitos somente o a fibra do buriti e as demais tanto com o cipó titica e a fibra da palha do buriti. Inclui-se também o compensado natural de $8 \mathrm{~mm}$ e o verniz industrial, no qual é utilizado como base das cestarias e dos vasos e que tem um preço elevado, o que acaba por elevar os custos de fabricação.

Nesse processo da terceira etapa temos como instrumentos de trabalho apenas as mãos no qual vão se trançando o cipó titica, que de acordo com a peça produzida tem-se uma técnica específica e que consiste basicamente na forma do traçado e na base apoio para a fabricação das peças artesanais.

\section{RESULTADOS E CONCLUSÃO}

Foram analisados todo o processo de produção das peças artesanais de cipó titica e fibra do buriti, que de uma forma geral o grupo tem algumas características importantes quanto a educação ambiental no qual podemos destacar que a de consciência ambiental, pois é feito um planejamento da coleta do cipó titica e da palha do buriti nas residências dos agricultores, que acontece de forma e períodos organizados, para não se esgotarem as materiais primas, fazendo com que tenha-se matéria prima durante todo o ano.

O processo de extração da matéria prima envolve toda a família, que em forma de mutirão fazem a coleta, possuindo cada membro da família uma função específica no processo que é dividido em: as mulheres e o esposos fazem a seleção e a retirada da matéria prima. 


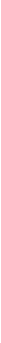

Figura 1- Processo de Extração e Beneficiamento do Cipó titica e da fibra da palha do buriti

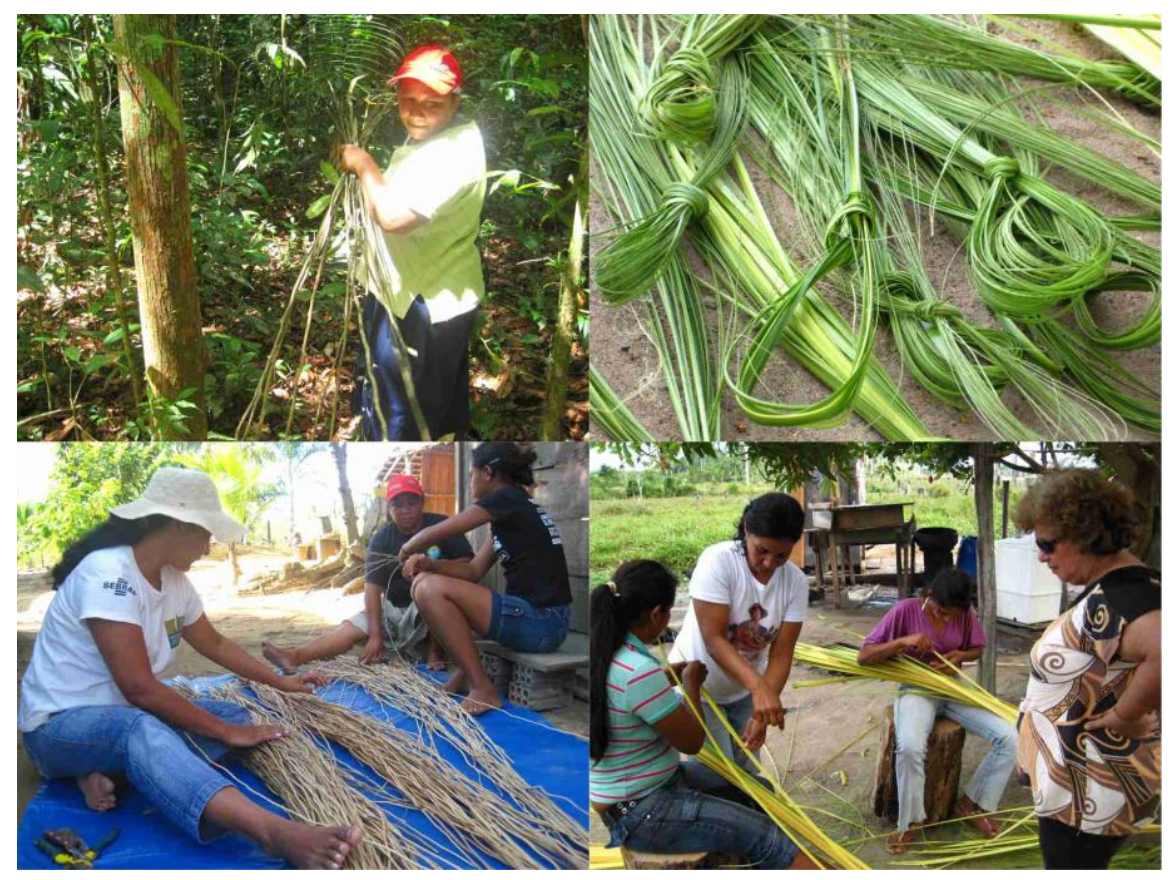

Fonte: SOUZA, Felipe Melo, 2008

$\mathrm{Na}$ figura podemos observar o processo de extração, preparação e beneficiamento do cipó titica e da fibra da palha do buriti, após o descasque do cipó titica, temos a seleção em função dos diâmetros além da divisão em feixes para o preparo de conservação através da utilização de água adicionado com bicarbonato de sódio. Na figura 2 abaixo temos a preparação do cipó titica, que é adicionado água e bicarbonato de sódio, onde é emergido os feixes enrolados do cipó titica, pouco mais de 5 minutos e logo após são retirados e colocados ao sol para a secagem.

Após a fabricação de compensado de $8 \mathrm{~mm}$ dos fundos das peças de cestarias e vasos, é feito furos na base de forma que por ele passem o cipó titica que é trançado de forma a ser produzido as cestarias. 


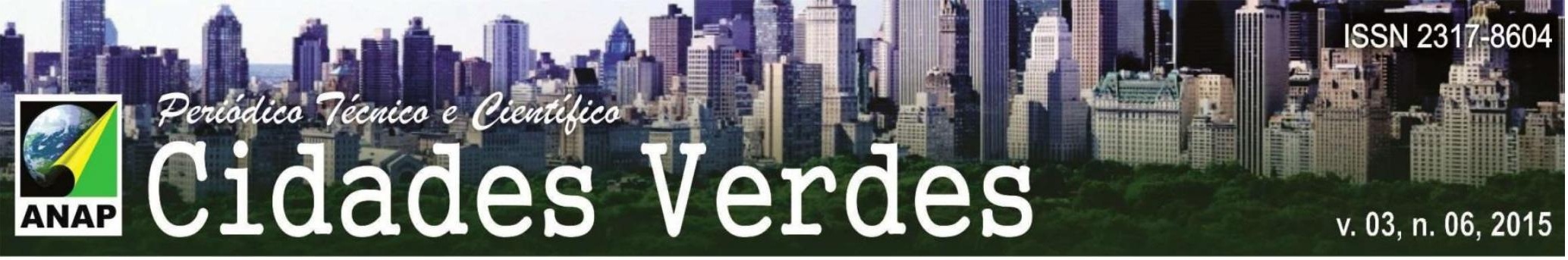

Figura 2: Processo de Preparação e Fabricação das cestaria de cipó titica

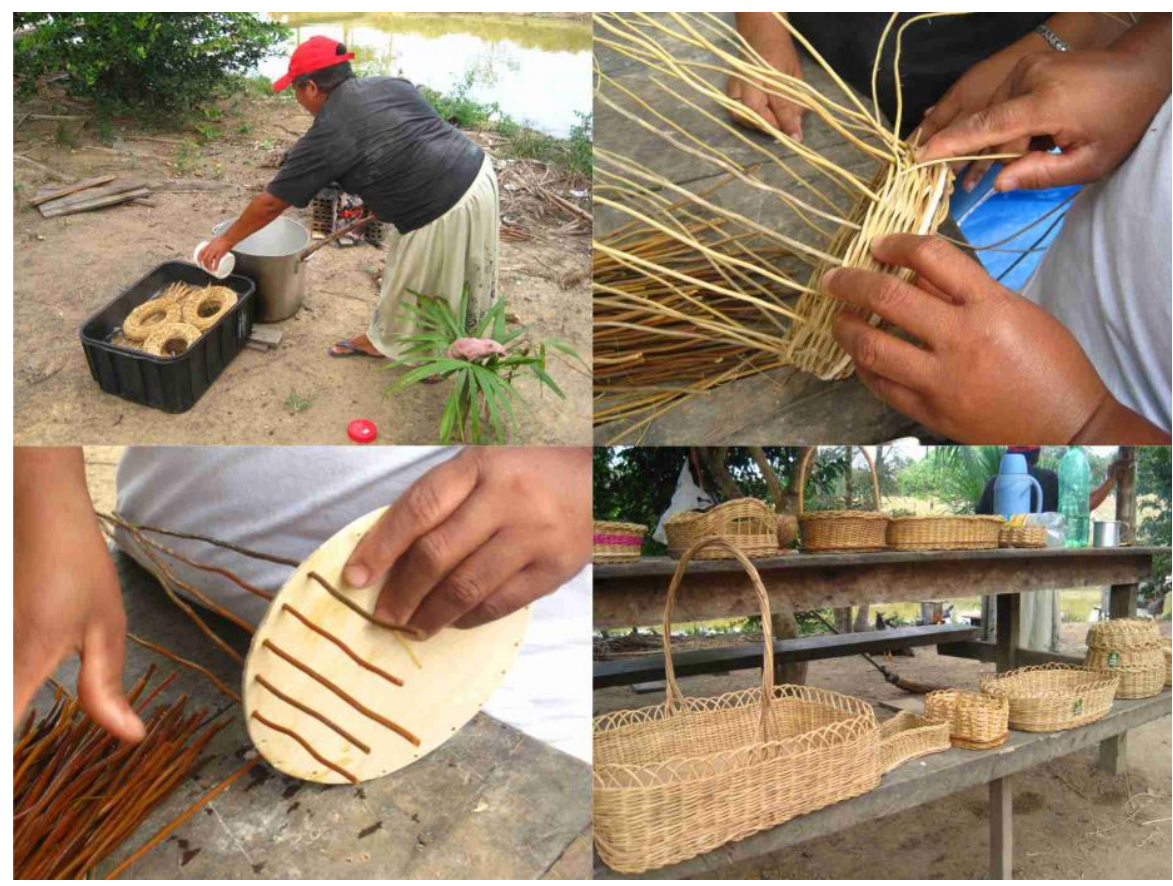

Fonte: SOUZA, Felipe Melo, 2008

\section{CONSIDERAÇÕES FINAIS}

A partir desta pesquisa, foi possível verificar o potencial encontrado no cipó titica e na palha do buriti que possui em grande quantidade na região sul do Estado de Roraima e que pode ser uma fonte de desenvolvimento em pequena escala do município e principalmente da comunidade de agricultores, considerando e principalmente conservando as condições ambientais de sua extração e beneficiamento no qual pode ser ampliado ao longo de toda extensão sul.

Nessa pesquisa também foi possível comprovar que tem a possibilidade de melhorar a produção artesanal, com a retirada de alguns produtos provenientes da indústria como o verniz e o compensado, reduzindo o custo e tornando o produto mais natural de forma a aumentar o valor de venda dos produtos.

Com uma educação ambiental agregada a essa atividade, tem-se a possibilidade de estabelecer conexões ainda maiores com as escolas, instituições e 
